\title{
Terapia fotodinâmica em carcinoma basocelular periocular: Relato de caso
}

\author{
Photodynamic therapy in periocular \\ basal cell carcinoma: Case report
}

Rachel Camargo Carneiro', Erick Marcet Santiago de Macedo', Pátricia Picciarelli de Lima², Suzana Matayoshi ${ }^{3}$

\begin{abstract}
RESUMO
Os autores descrevem a aplicação de terapia fotodinâmica com cloridrato de aminolevulinato de metila (Metivix®) em uma paciente com carcinoma basocelular padrão misto (nodular e infiltrativo) em pálpebra inferior de olho direito. Os efeitos colaterais sobre o olho foram avaliados semanalmente. Foi submetida à biòpsia incisional com punch de $2 \mathrm{~mm}$ para controle de cura após 12 semanas de tratamento. $\mathrm{O}$ anátomopatológico revelou ausência de neoplasia. O tratamento padrão ouro reconhecido mundialmente é a exérese da lesão, porém a terapia fotodinâmica com cloridrato de aminolevulinato de metila (MAL) surge como uma opção terapêutica à cirurgia.

Descritores: Carcinoma basocelular/quimioterapia; Fotoquimioterapia; Neoplasias palpebrais; Antineoplásicos/uso terapêutico; Biópsia; Relatos de casos
\end{abstract}

\begin{abstract}
The authors report the use of photodynamic therapy with methyl aminolevulinate (Metvix®) in a patient with nodular and infiltrative basal cell carcinoma in the right lower eyelid. Side effects on the eye were evaluated weekly. After 12 weeks of treatment, to confirm cure the patient was submitted to a 2-mm punch biopsy, the anatomopathological findings of which were negative for neoplasia. Photodynamic therapy with methyl aminolevulinate was shown to be an attractive alternative to surgical excision-the current gold standard treatment worldwide.

Keywords: Basal cell carcinoma/drug therapy; Photochemiotherapy; Eyelid neoplasms; Antineoplastic drugs/therapeutic use; Biopsy; Case reports
\end{abstract}

\footnotetext{
1 Pós-graduando do Setor de Plástica Ocular da Clínica Oftalmológica do Hospital das Clínicas da Faculdade de Medicina da Universidade de São Paulo (USP) - São Paulo (SP), Brasil;

${ }^{2}$ Médica do Serviço de Patologia do Hospital das Clínicas da Faculdade de Medicina da Universidade de São Paulo (USP) - São Paulo (SP), Brasil;

${ }^{3}$ Professora associada e Chefe do Setor de Plástica Ocular da Clínica Oftalmológica do Hospital das Clínicas da Faculdade de Medicina da Universidade de São Paulo (USP) - São Paulo (SP), Brasil.

Trabalho realizado no Setor de Plástica Ocular da Clínica Oftalmológica do Hospital das Clínicas da Faculdade de Medicina da Universidade de São Paulo (USP) - São Paulo (SP), Brasil.
}

Os autores declaram não haver conflitos de interesse

Recebido para publicação em: 21/3/2012 - Aceito para publicação em: 28/6/2012

Rev Bras Oftalmol. 2012; 71 (6): 394-6 


\section{INTRODUÇÃO}

A terapia fotodinâmica (TFD) caracteriza-se pela indução da citotoxicidade das células proliferativas através de uma fonte de luz. Para que isso ocorra, são necessários um agente fotossensibilizante, luz e oxigênio ${ }^{(1)}$.

O cloridrato de aminolevulinato de metila (MAL) derivado do 5-ALA apresenta maior seletividade pelas células tumorais e sendo mais lipofílico consegue penetrar profundamente na lesão ${ }^{(2)}$, sendo também o único com registro na ANVISA ( ${ }^{\circ}$ MS-1.2916.0065.001-6) para o tratamento do carcinoma basocelular superficial e da ceratose actínica.

Durante a terapia fotodinâmica, o agente fotossensibilizante acumula-se, preferencialmente, nas células tumorais após administração tópica e é ativado na presença de luz vermelha variando de 570 a $670 \mathrm{~nm}$. Lâmpadas LED desenvolvidas para emitir uma luz vermelha visível também demonstraram resultados satisfatórios ${ }^{(3)}$. Sua ativação permite que interaja com substratos biológicos para formar radicais livres ou transferir sua energia diretamente ao oxigênio intracelular, formando oxigênio singlete altamente reativo que é responsável pela morte celular. A formação de oxigênio singlete é a reação predominante na TFD e o principal fator para a ocorrência da citotoxicidade ${ }^{(1)}$.

Existem evidências cada vez maiores de que a terapia fotodinâmica cause morte do tumor pela oclusão dos vasos que o alimentam, bem como por efeito citotóxico direto sobre suas células. Esse mecanismo despertou o interesse em utilizar a terapia fotodinâmica no tratamento de doenças oftalmológicas caracterizadas por neovascularização, como a degeneração macular, permitindo a preservação da retina neurosensorial ${ }^{3(-6)}$.

O carcinoma basocelular (CBC) é a neoplasia mais comum da região periocular e sua incidência continua a aumentar $10 \%$ ao ano. ${ }^{7} \mathrm{O}$ tratamento padrão-ouro é a exérese cirúrgica da lesão, porém a terapia fotodinâmica surge como uma opção terapêutica para o tratamento clínico como no presente relato.

\section{Relato de Caso}

Paciente feminina, 69 anos, Fitzpatrick tipo IV, apresentando lesão nódulo-ulcerativa em pálpebra inferior de olho direito há aproximadamente sete meses. O crescimento foi lento e apresentava sangramento e prurido ocasionalmente.

A lesão media aproximadamente $19,30 \mathrm{~mm}$ em seu maior diâmetro (Figura 1).

Foi realizada biópsia incisional com trépano de $2 \mathrm{~mm}$ no local mais típico do tumor. O exame revelou a presença de carcinoma basocelular padrão misto nodular (sólido) e infiltrativo. A epiderme é elevada com aplanamento da junção dermoepidérmica. Grandes lóbulos de células basalóides atípicas invadem a derme superficial e profunda em um padrão nodular (A). Componente de padrão infiltrativo (B) em derme profunda. Coloração hematoxilina e eosina (HE), menor aumento (100X) (Figura 2A e 2B).

$A$ paciente foi orientada em relação às opções terapêuticas, sendo que optou pelo tratamento conservador em duas sessões (abaixo discriminado) com intervalo de uma semana entre uma e outra.

O procedimento foi ambulatorial, a medicação aplicada por um dos autores seguindo as seguintes etapas:

1. Instilação de 1 gota de colírio anestésico (Anestalcon ${ }^{\circledR}$ ) em fórnice conjuntival;

2. Assepsia e antissepsia;

3. Infiltração anestésica com lidocaína sem vasoconstritor (Xylocaína ${ }^{\circledR}$ );

4. Curetagem da lesão com cureta dermatológica de $2 \mathrm{~mm}$;

5. Aplicação tópica do creme na lesão ultrapassando os limites visíveis do tumor (5 a $10 \mathrm{~mm})$;

6. Curativo com oclusor palpebral para evitar a exposição à luz durante 3 horas;

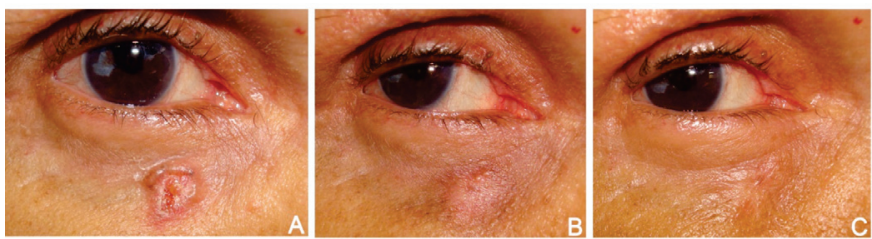

Figura 1: (A) Pré-tratamento; (B) 3 meses pós tratamento - cisto epidérmico e hipopigmentação da pele; (C) 4 meses após tratamento

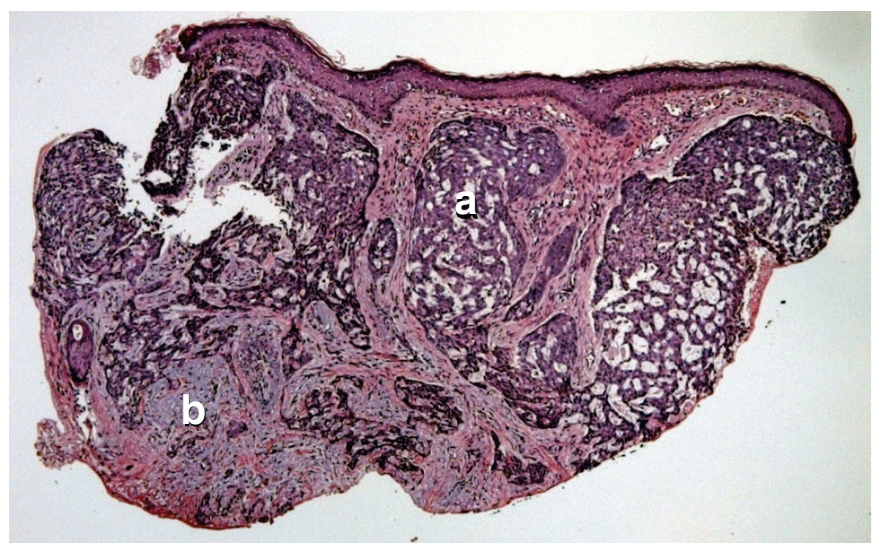

Figura 2: $\mathrm{O}$ exame revelou a presença de carcinoma basocelular padrão misto nodular (a) e infiltrativo (b) coloração hematoxilina e eosina (HE), menor aumento (100X)

7. Retirada do oclusor palpebral após 3 h e limpeza da área com SF $0,9 \%$;

8. Instilação de 1 gota de colírio anestésico (Anestalcon ${ }^{\circledR}$ ) no fundo de saco conjuntival e colocado uma lente protetora escleral; 9. Imediatamente, a lesão foi exposta a luz vermelha (Aktilite ${ }^{\circledR}$ ), com espectro contínuo de $570-670 \mathrm{~nm}$ e dose de luz total de $75 \mathrm{~J} /$ $\mathrm{cm} 2$ na superfície da lesão, por um período de $8 \mathrm{~min}$.

A paciente não referiu dor durante o procedimento, na segunda aplicação relatou leve ardor. Na avaliação imediata após as duas aplicações, observou-se edema e hiperemia local. Recomendou-se o uso de protetor solar, colírio lubrificante 1 gota 3 vezes ao dia e compressas geladas.

O acompanhamento oftalmológico foi semanal até completar um mês, mensal até três meses. A acuidade visual foi preservada ao longo do tratamento. Após uma semana da segunda sessão de TFD-MAL, observou-se hiperemia conjuntival e hipopigmentação da pele que regrediram nas semanas seguintes. No terceiro mês observou-se a presença de um cisto que revelou ser benigno (cisto epidermóide) (Figura 1).

Após 90 dias de seguimento foi submetida à biópsia incisional com trépano de $2 \mathrm{~mm}$. O procedimento foi guiado pela imagem obtida anterior ao tratamento porque não apresentava lesão maligna visível. A análise do anátomopatológico para controle histológico de cura revelou um fragmento de pele sem evidências de neoplasia e um cisto epitelial (a) com queratinização do tipo epidérmica (cisto epidermóide). A derme superficial apresentou leve processo inflamatório crônico linfocitário (seta), fibrose e elastose solar (b). HE (100X) (Figura 3a e b). recidiva.

O seguimento atual é de 8 meses sem sinais clínicos de

\section{Discussão}

A terapia fotodinâmica com cloridrato de aminolevulinato de metila já foi amplamente investigada em estudos clínicos dermatológicos. Todos os estudos realçaram a segurança e os resultados funcionais e cosméticos e reportaram uma taxa de 


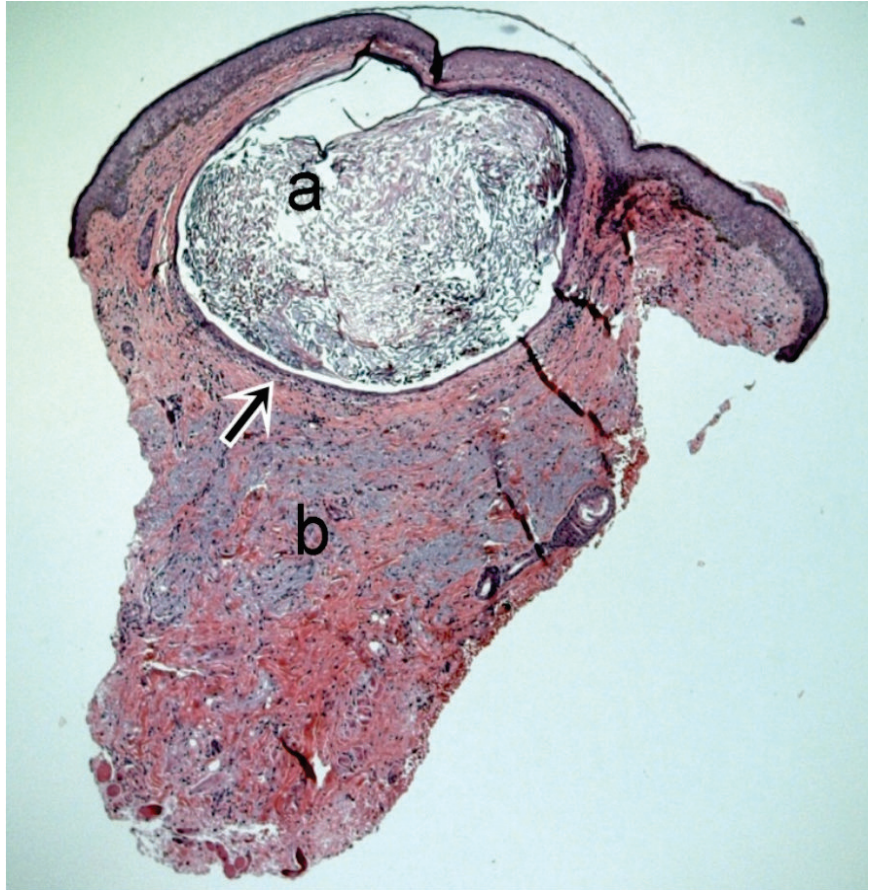

Figura 3: Fragmento de pele sem evidências de neoplasia; cisto epitelial (a) com queratinização do tipo epidérmica (cisto epidermóide); A derme superficial apresentou leve processo inflamatório crônico linfocitário (seta), fibrose e elastose solar (b); HE (100X)

cura entre 75 a $93 \%$ para o CBC nodular e entre 83 a $96 \%$ para o CBC superficial com tempo de seguimento variando de 2 a 5 anos. $\mathrm{O}$ uso de drogas tópicas na terapia fotodinâmica para carcinoma basocelular nodular é controverso, porque acreditam que tanto a luz quanto a penetração da droga através das camadas da pele limitariam os resultados ${ }^{(8)}$.

Em oftalmologia há poucos estudos relatados, o uso da TFD com ácido 5-aminolevulínico foi descrita em três estudos e em apenas dois com cloridrato de aminolevulinato de metila. ${ }^{(9-}$ 14) A TFD-MAL é realizada após curetagem da superfície da lesão e MAL por ser mais lipofílico é capaz de penetrar mais profundamente na lesão. Além disso, MAL apresenta seletividade superior ao ALA, poupando as células normais vizinhas, parte dessa ação é justificada por sua captação acelerada pelas células tumorais seja por transporte ativo como passivo.

Para o oftalmologista, a terapia fotodinâmica com aplicação de um agente fotossensibilizante tópico facilita o tratamento do $\mathrm{CBC}$ periocular devido à simplicidade do método. Dor e ardência podem ocorrer durante o procedimento e podem ser amenizados com soro fisiológico $0,9 \%$, não sendo necessário no caso descrito acima. A limitação do procedimento está relacionada ao custo da medicação fotossensibilizante.

No presente relato, observamos a cura histológica através do trépano de $2 \mathrm{~mm}$, trata-se de um basocelular padrão misto, nodular e infiltrativo. Os outros trabalhos na região periocular não realizaram biópsia para controle de cura, além disso os subtipos histológicos eram superficial e nodular. $\mathrm{O}$ acompanhamento será com biópsias seriadas a cada 6 meses devido ao padrão infiltrativo.

Nas avaliações oftalmológicas periódicas, não foram observados danos visuais permanentes. Recomendamos a utilização de colírio lubrificante 3 vezes ao dia, após tratamento para prevenção de alterações na superfície ocular e compressas geladas para redução dos efeitos térmicos sobre a pele. Na literatura o estudo realizado em margem palpebral orientou o uso de clorafenicol 5\% com dexametasona $1 \%$ para prevenção de infecção e irritação ocular, porém não descreveram a presença de alterações oculares ${ }^{(14)}$.

Do ponto de vista estético, observamos uma discreta hipopigmentação transitória da pele na região tratada. (Figura 1B). Trata-se de uma paciente Fizpatrick IV, na literatura é comum observar esse tipo de alteração pós-TFD em pele Fizpatrick III e IV. São alterações transitórias e usualmente resolvem em até 6 meses.

Um cisto epidérmico no terceiro mês pós-tratamento foi observado. O cisto tinha uma dimensão menor que $2 \mathrm{~mm}$ e foi retirado com o próprio trépano de $2 \mathrm{~mm}$ durante a biópsia para controle de cura, realizada 90 dias após a TFD. Na literatura há relato de dois casos de cisto epidérmico pós TFD-MAL em CBC superficial(15), mas ainda não descrito em CBC misto (nodular e infiltrativo).

A terapia fotodinâmica é uma opção terapêutica válida para o tratamento ambulatorial do carcinoma basocelular nodular, porém estudos maiores devem ser realizados para mensurar os efeitos colaterais sobre o olho, além de avaliar recidivas principalmente nos padrões mistos como o caso em questão.

\section{REFERÊNCIAS}

1. Torezan LAR. Avaliação da eficácia da terapia fotodinâmica com ácido 5-delta aminolevulínico (ALA) tópico no carcinoma basocelular [dissertação]. São Paulo: Faculdade de Medicina da Universidade de São Paulo; 2000.

2. Briefing document for FDA Advisory Committee Meeting for photodynamic therapy with methyl aminolevulinate cream for treatment of basal cell carcinoma. NDA 21-576. [cited 2011 Jun 12]. Avaliável from: http://www.fda.gov/ohrms/dockets/ac/03/ briefing/3983B2_02_PhotoCure-Briefing \%20Document.pdf

3. Fritsch C, Goerz G, Ruzicka T. Photodynamic therapy in dermatology. Arch Dermatol. 1998;134(2):207-14

4. Lucena EG, Miller JW. Benzoporphyrin (verteporfin) photodynamic therapy for choroidal neovascularization in age-related macular degeneration. Arq Bras Oftalmol. 2000;63(6):511-8.

5. Schmidt-Erfurth U, Miller JW, Sickenberg M, Laqua H, Barbazetto I, Gragoudas ES, et al. Photodynamic therapy with verteporfin for choroidal neovascularization caused by age-related macular degeneration: results of retreatments in a phase 1 and 2 study. Arch Ophthalmol. 1999:117(9):1177-87. Erratum in Arch Ophthalmol. 2000;118(4):488.

6. Miller JW, Schmidt-Erfurth U, Sickenberg M, Pournaras CJ, Laqua H Barbazetto I, et al. Photodynamic therapy with verteporfin for choroidal neovascularization caused by age-related macular degeneration: results of a single treatment in a phase 1 and 2 study. Arch Ophthalmol. 1999;117(9):1161-73. Erratum in Arch Ophthalmol. 2000;118(4):488.

7. Wong CS, Strange RC, Lear JT. Basal cell carcinoma. BMJ. 2003:327(7418):794-8. Review.

8. Torezan L, Niwa ABM, Festa Neto C. Terapia fotodinâmica em dermatologia: princípios básicos e aplicações. An Bras Dermatol. 2009;84(5):445-59.

9. Wang I, Bauer B, Andersson-Engels S, Svanberg S, Svanberg K. Photodynamic therapy utilising topical delta-aminolevulinic acid in non-melanoma skin malignancies of the eyelid and the periocular skin. Acta Ophthalmol Scand. 1999;77(2):182-8.

10. Hoerauf H, Hüttmann G, Diddens H, Thiele B, Laqua H. [Photodynamic therapy of eyelid basalioma after topical administration of deltaaminolevulinic acid]. Ophthalmologe. 1994;91(6): 824-9. German.

11. Hintschich C, Feyh J, Beyer-Machule C, Riedel K, Ludwig K. Photodynamic laser therapy of basal-cell carcinoma of the lid. Ger J Ophthalmol. 1993;2(4-5):212-7.

12. Puccioni M, Santoro N, Giansanti F, Ucci F, Rossi R, Lotti T, Menchini U. Photodynamic therapy using methyl aminolevulinate acid in eyelid basal cell carcinoma: a 5-year follow-up study. Ophthal Plast Reconstr Surg. 2009;25(2):115-8.

13. Kotimäki J. Photodynamic therapy of eyelid basal cell carcinoma. J Eur Acad Dermatol Venereol. 2009;23(9):1083-7.

14. Togsverd-Bo K, Haedersdal M, Wulf HC. Photodynamic therapy for tumors on the eyelid margins. Arch Dermatol. 2009;145(8):944-7

15. Ghaffar SA, Clements SE, Lear JT. Epidermoid cysts mimicking recurrence of superficial basal cell carcinoma following photodynamic therapy. Clin Exp Dermatol. 2007;32(2):223-4.

\section{Autor correspondente:}

Rachel Camargo Carneiro

Rua dr. Albuquerque Lins, no 1328 - apto. 31

CEP 01230-000 - São Paulo - (SP), Brasil

E-mail: rccarneiro@msn.com 